\title{
No more "frame-shaming" Using critical reflection to facilitate change
}

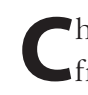

hange can elicit an array of emotions from the people that help drive that change. For example, the ACRL Framework for Information Literacy for Higher Education sparked a lively discussion among librarian professionals. That debate continues mostly around the use and pedagogical value of the frames. Some librarians expressed their frustration with the changes and some embraced the new Framework, while some are still trying to understand where it fits in their context.

In my observations on listservs, training, and informal conversations, it seems the lack of acknowledging the emotional experience of our colleagues, particularly those who are outwardly expressing discontent, is a cause for slow change. Those who expressed frustration are often met with their colleagues' responses that defend ACRL's new document, also known as "frame-shaming." While I have empathy for both sides, the culture of debate in academia may impede on the adoption of the Framework.

Jan Fook and Gurid Aga Askeland write that "an adversarial culture which conditions us to believe that the 'truth' can be arrived at only through debate or 'fight' between opposing sides ... tends to oversimplify complexities and to emphasize differences."1

While approaching our colleagues with logical arguments may seem reasonable, it may be more effective to apply a critical reflective approach in engaging in conversa- tions about pedagogy to drive change. We can develop an empathetic understanding of our colleagues' teaching experience and context as well as remove any assumptions about them and their working environment. Through this understanding, we may be able to coach our colleagues' and encourage change and action.

\section{What is critical reflection?}

Critical reflection is the recognition of how our perspective is informed and constructed based on our belief systems and thus our assumptions prevent us from empathizing and, ultimately, effectively addressing our colleagues' concerns. ${ }^{2}$ These assumptions may not be clear or evident in our initial thinking. In teacher education, Stephen D. Brookfield outlined two characteristics of critical reflection:

1. Understanding how considerations of power undergird, frame, and distort educational processes and interactions.

2. Questioning assumptions and practices that seem to make our teaching lives easier but actually work against our own best longterm interests." ${ }^{3}$

For example, a common assumption that

Silvia Vong is collaborative learning librarian at the University of St. Michael's College in the University of Toronto, email: silvia.vong@utoronto.ca

๑ 2017 Silvia Vong 
could be made about the adoption of the ACRL Framework is that all universities or colleges have similar cultural, social, and political landscapes. Most of us may be instructional librarians, but that is where the similarities stop. Our context can range in terms of resources, support from colleagues and administration, and education.

\section{How do you critically reflect?}

There are some strategies to help us critically reflect on our assumptions. By framing and reflecting on our thinking, we can breakdown assumptions and address them before we address our colleagues. The one strategy that I will focus on (since it is most relevant to this particular context) is the ideology critique. ${ }^{4}$ The approach tends to pair with a critical incident in reflective practice. This means that I would choose and describe an incident at work, identify the ideologies that are present, and discuss alternative methods. David Tripp frames it as four steps:

1. Examine an incident and identify the dominant view or ideology present.

2. Discuss gaps and contradictions in statements and viewpoints presented in your description.

3. Identify the individual(s) or group(s) that are disadvantaged by the ideology and how the dominant view does not acknowledge them.

4. Create alternative ways that include or consider different perspectives and ideologies. ${ }^{5}$

Below is an example of Tripp's ideology critique applied to an interaction I experienced. The incident was related to my delivery of a series of workshops for my library colleagues in the early stages of the Framework. There were three workshops that were themed around two frames that were designed with a team of librarians and delivered in an interactive way (e.g., we designed activities around a frame) with focus on the practicality of the Framework.

Intended meaning: I wanted to engage other teaching librarians at my library with the ACRL Framework early through work- shops that discussed the application of the Framework. I wanted to make the Framework more practical and easy to understand.

Gaps and contradictions: The concept of active learning through activities and handson work, such as designing a lesson based on the Framework, is dependent on the idea that my colleagues:

- have a strong knowledge of threshold concepts or learning theory,

- have read and understood the ACRL Framework,

- have the same reservations as I do with the ACRL information literacy standards,

- have the resources and time to integrate the Framework into their work, and

- have opportunities and support from faculty and administration to implement changes to their information literacy program.

Overall, I have made the assumption that all my colleagues have various resources, including knowledge, resources, and support, to implement the Framework in their working environment.

Benefit and harm: Those who may be most comfortable with the Framework may be librarians with full support from administration and their colleagues, as well as resources. Those who are worst served in this scenario would be those with little understanding of the Framework and may not have the privilege of access to teaching resources or training.

Alternative: The workshops should have had a pre-assessment to understand the various contexts and unique environments of my colleagues so that we can offer support or more discussion around implementing change in their own environment. Moreover, discussion and buy-in from administration and faculty could help ease the change and transition. More importantly, there should have been a discussion around resources and implementation to support colleagues with little resources before the workshops on designing lessons.

Upon realizing the many assumptions I made with my colleagues, I began to understand and empathize with their frustrations. 
I began to think and brainstorm ideas on how to transition the content in a more inclusive way beyond the basic introductions done through webinars and conference presentations. Rather than present the ACRL Framework immediately, I needed to understand my colleagues' context and current teaching philosophies. My colleagues did not need a repeat of all the workshops and sessions they had attended or would attend. Rather, they needed help unpacking the document and more importantly, contextualizing the document and identifying where resources need to be allocated or are required.

\section{Conclusion}

I am guilty of frame-shaming. However, as I listen and reflect on my colleagues' reactions and experiences, I can empathize and hope that I can better facilitate a discussion to move towards more positive action. Brookfield writes that ". . . those of us who are trying to get colleagues to identify and question their assumptions, or to look at their practice through different lenses, must do the same." 6

Often the root of our reactions and actions are not always obvious. To better understand my colleagues, I needed to explore the assumptions I made with the workshop participants.

\section{Notes}

1. Jan Fook and Gurid Aga Askeland, "Challenges of Critical Reflection: 'Nothing Ventured, Nothing Gained,' Social Work Education, 26, no. 5 (2007): 528.

2. Stephen D. Brookfield, Becoming a Critically Reflective Teacher (San Francisco, Jossey-Bass, 1995), 8.

3. Ibid.

4. David Tripp, Critical Incidents in Teaching: Developing Professional Judgement (New York: Routledge, 1993).Tripp, Critical Incidents in Teaching, 59.

5. Tripp, Critical Incidents in Teaching, 59.

6. Brookfield, Becoming a Critically Reflective Teacher, 205.

("The enemy of the good. ..," continues from page 374)

attempt to persuade to pay open access charges) authors who are publishing with open access mandates from their funder or institution. There should not be differences between posting in an institutional repository and a personal webpage.

Current practices help perpetuate an artificial monopoly that inhibits knowledge dissemination and growth while giving the appearance of openness. The Internet has not merely increased access and availability of resources, it has opened an avenue to sharing that is inevitable. Like water through the cracks, information will find a path of least resistance, and it is in publisher's' best interest to promote a system that enables reasonable compliance for librarians and authors. As publishers struggle with illegal downloads and the potential security threat of platforms such as Sci-Hub, ${ }^{6}$ it behooves them to treat libraries and repositories as partners in the dissemination of knowledge rather than as adversaries. Ultimately, the more access researchers have to articles, the more those articles get cited, ${ }^{7}$ which increases impact factor and journal prestige. Since libraries need to maintain subscriptions for intuitional accreditation and performance, and increased citations benefit journals, ease of institutional repository deposit should be seen as an easy win for publishers.

\section{Notes}

1. World Intellectual Property Organization, "Berne Convention for the Protection of Literary and Artistic Works," www.wipo.int /treaties/en/ip/berne/.

2. Nancy Sims, "It's all the same to me! Copyright, contracts, and publisher self-archiving policies," College \& Research Libraries News 76 no. 11 (2016) 578-581.

3. Jisc, "Publisher copyright policies and self-archiving," www.sherpa.ac.uk

(continues on page 401) 